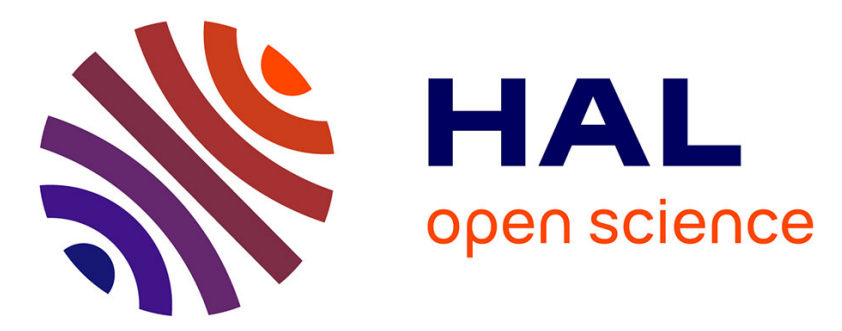

\title{
Long Range Magnetic Ordering and Magneto-(di) electric Effect in a New Class of High Entropy Spinel Oxide
}

Sourav Marik, Deepak Singh, Bruno Gonano, Fabien Veillon, D. Pelloquin, Yohann Bréard

\section{To cite this version:}

Sourav Marik, Deepak Singh, Bruno Gonano, Fabien Veillon, D. Pelloquin, et al.. Long Range Magnetic Ordering and Magneto-(di) electric Effect in a New Class of High Entropy Spinel Oxide. Acta Materialia, 2019, 183, pp.107-110. 10.2139/ssrn.3507452 . hal-03082280

\section{HAL Id: hal-03082280 https://hal.science/hal-03082280}

Submitted on 24 Nov 2021

HAL is a multi-disciplinary open access archive for the deposit and dissemination of scientific research documents, whether they are published or not. The documents may come from teaching and research institutions in France or abroad, or from public or private research centers.
L'archive ouverte pluridisciplinaire HAL, est destinée au dépôt et à la diffusion de documents scientifiques de niveau recherche, publiés ou non, émanant des établissements d'enseignement et de recherche français ou étrangers, des laboratoires publics ou privés. 


\title{
Long Range Magnetic Ordering and Magneto-(di) electric Effect in a New Class of High Entropy Spinel Oxide
}

\author{
Sourav Marik ${ }^{\mathrm{a} *}$, Deepak Singh ${ }^{\mathrm{b}}$, Bruno Gonano ${ }^{\mathrm{a}}$, Fabien Veillon ${ }^{\mathrm{a}}$, Denis Pelloquin ${ }^{\mathrm{a}}$, Yohann Bréard ${ }^{\mathrm{a}}$ \\ aLaboratory Crismat, UMR6508 CNRS, Normandie University, ENSICAEN, UNICAEN, 6 bd Maréchal Juin, 14050 Caen cedex 4, France \\ bISIS facility, STFC Rutherford Appleton Laboratory, Harwell Science and Innovation Campus, Oxfordshire OX11 0QX, United Kingdom
}

\begin{abstract}
High-entropy stabilized oxide materials have gained a significant research interest in recent times due to their unique structural features and indeed hold promise for accessing unprecedented combinations of physicochemical properties. In the present work, a new class of high entropy spinel material with composition $\left(\mathrm{Mg}_{0.2} \mathrm{Co}_{0.2} \mathrm{Ni}_{0.2} \mathrm{Cu}_{0.2} \mathrm{Zn}_{0.2}\right) \mathrm{Cr}_{2} \mathrm{O}_{4}$ is introduced. Structural and microstructural characterizations are carried out using the combination of room temperature X-ray diffraction, scanning electron microscope - energy dispersive X-ray spectroscopy (SEM-EDS) elemental mapping and high-angle annular dark-field (HAADF), annular bright field (ABF) scanning transmission electron microscopy measurements. All these measurements highlight that the sample crystallizes in a cubic spinel structure with an excellent chemical homogeneity at the nanoscale. Despite strong disorder (magnetic and structural), dc, ac magnetometry and specific heat highlight a predominant antiferromagnetic (AFM) behaviour at $35 \mathrm{~K}$ in this highly disordered single-phase material. A peak in the dielectric measurement is observed at the AFM ordering temperature, indicating the possibility of magneto-electric coupling at that temperature. Our study, for the first time, highlights the feasibility to accommodate multiple elements onto a single sublattice in a complex spinel structure and opens new possibilities to design and tailor functional properties in high entropy stabilized correlated electron systems.
\end{abstract}

\section{Introduction}

Development of advanced materials with novel functional structures and improved - tailorable functionalities is the key to the continuous progress of materials science. In this context, the advent of a new materials design strategy namely high entropy stabilization route, which is evolved with the discovery of high entropy alloys [1-3], opens the possibility to stabilize the phases by high configurational entropies, and have drawn intense research interest in recent times [1-20]. The key point of the highentropy design strategy is the use of the combination of a five or more number of cations in equiatomic or near equiatomic ratio. The high mixing entropic contribution $\left(\Delta \mathrm{S}_{\text {mixing }}\right)$ to the decreased Gibbs free energy stabilizes disordered solid solution phases in a simple structure and overcome the usual enthalpy driven phase separation generally observed in heavily doped systems.

High entropy oxides (HEOs) are the extension of the concept of high-entropy alloys (HEAs) to entropy-stabilized oxides [7 -14]. In 2015, Rost et al. [7] discovered the first HEO $\left[\left(\mathrm{Mg}_{0.2} \mathrm{Co}_{0.2} \mathrm{Ni}_{0.2} \mathrm{Cu}_{0.2} \mathrm{Zn}_{0.2}\right) \mathrm{O}\right]$ having five different cations, in equiatomic ratios. Such oxide materials, stabilized by high configurational entropy are located at the centre of a multinary phase diagram. This domain of materials composition is seldom studied, and therefore unexpected multifunctional properties can be anticipated. Recently, investigations into this new class of oxide systems have resulted in several intriguing discoveries. Examples include superior Li storage capacity retention capabilities [9,10,21], room temperature $\mathrm{Li}+$ superionic conductivity [22], catalytic properties [23], colossal dielectric constants [24], narrow and adjustable band gaps [25] and long-range magnetic ordering $[11,13]$. Nevertheless, the field of HEOs is at its early stage, and many of the materials are remain to be explored.

Herein we report synthesis, structure and physical properties of a new class of high entropy spinel oxide with composition $\left(\mathrm{Mg}_{0.2} \mathrm{Co}_{0.2} \mathrm{Ni}_{0.2} \mathrm{Cu}_{0.2} \mathrm{Zn}_{0.2}\right) \mathrm{Cr}_{2} \mathrm{O}_{4}$. For the last two decades, chromium-based spinel materials $\left(\mathrm{ACr}_{2} \mathrm{O}_{4}\right)$ have been a fertile playground for experimental and theoretical investigations on the physics of geometrical frustration [26-30]. At the same time, they are considered of significant interest for a range of potential applications [31-33]. The octahedrally coordinated $\mathrm{Cr}$ atom form a three-dimensional network similar to a pyrochlore lattice. The high geometrical frustration in this pyrochlore lattice originates intriguing physical effects (such as multiferroics, Spin-Peierls-like phase transition, quantum magnetic frustration) as a correlation of structural and spin degrees of freedom. A-site cations, on the other hand, occupy the eightfold tetrahedral sites. Materials with nonmagnetic cations in the A site are geometrically frustrated in nature and facilities studies of these highly degenerate ground states $[24,25]$. Magnetic $\mathrm{A}^{2+}$ cations introduce different crystal fields and therefore, can provide exciting aspects of magnetism and magnetoelectric effects [24, 26-28]. Here, utilizing the high entropy stabilization route, we have synthesized a new class of high entropy spinel oxide with composition $\left(\mathrm{Mg}_{0.2} \mathrm{Co}_{0.2} \mathrm{Ni}_{0.2} \mathrm{Cu}_{0.2} \mathrm{Zn}_{0.2}\right) \mathrm{Cr}_{2} \mathrm{O}_{4}$. A detailed study on the structure, microstructure and physical properties of this new material are presented here. Due to existence of several magnetic and nonmagnetic cations with different electron configurations and their random distribution in the structure a robust structural disorder is anticipated, and, one may at a glance expect a spin-glasslike magnetic state. However, on the contrary, the present HEO material exhibits long-range AFM ordering.

\section{Experimental Section}

Synthesis. The sample with composition $\left(\mathrm{Mg}_{0.2} \mathrm{Co}_{0.2} \mathrm{Ni}_{0.2} \mathrm{Cu}_{0.2} \mathrm{Zn}_{0.2}\right) \mathrm{Cr}_{2} \mathrm{O}_{4}$ was synthesized by the standard solid-state reaction route, using the stoichiometric amounts of $\mathrm{MgO}(99.9 \%), \mathrm{Co}_{3} \mathrm{O}_{4}(99.9 \%), \mathrm{NiO}(99.9 \%), \mathrm{CuO}$ (99.9\%), $\mathrm{ZnO}$ (99.9\%) and $\mathrm{Cr}_{2} \mathrm{O}_{3}$ (99.9\%). The stoichiometric amounts of the precursors were carefully mixed and pressed in the form of bars. The sample was then heated at $1100^{\circ} \mathrm{C}$ for 24 hours followed by the water quench. This step was repeated twice. 
X-ray diffraction. X-ray diffraction patterns were collected at room temperature in an X'pert Pro diffractometer working with the $\mathrm{CuK}_{\alpha}$ radiation.

Electron microscopy. Energy Dispersive X-Ray Spectroscopy (EDS) mappings are carried out on ZEISS SUPRA 55 scanning electron microscope (SEM). The high-angle annular dark-field (HAADF), annular bright field (ABF) scanning transmission electron microscopy (STEM), and EDS analyses were performed on a JEOL ARM-200F cold FEG probe image aberration corrected microscope operated at $200 \mathrm{kV}$ and equipped with a large solid-angle CENTURIO EDX detector.

Magnetic measurements. Direct current (dc) magnetic measurements were performed by using a Quantum Design superconducting quantum interference device (MPMS, Quantum Design). Alternating current (ac) susceptibility measurements (ac excitation $=10 \mathrm{Oe}$, dc magnetic field $=0 \mathrm{Oe}$ ) were carried out using the ac Measurement System (ACMS) attachment in a Physical Properties Measurement System (PPMS, Quantum Design).

Specific heat. Specific heat measurement was performed by the two tau time- relaxation method using the PPMS in zero magnetic field.

Dielectric measurements. The dielectric measurement were carried out as a function of temperature and magnetic field for various frequencies using an LCR meter (Agilent 4284A) with a home-made sample insert for a Physical Properties Measurement System (PPMS, Quantum Design). Silver paint was used to make the parallel plate capacitor of a pressed rectangular shaped polycrystalline sample.

\section{Results and Discussion}

3.1. Crystal structure, microstructure and chemical homogeneity. The figure 1(a) shows the Le Bail profile fitting of the room temperature (RT) powder X-ray diffraction patterns (XRD) for $\left(\mathrm{Mg}_{0.2} \mathrm{Co}_{0.2} \mathrm{Ni}_{0.2} \mathrm{Cu}_{0.2} \mathrm{Zn}_{0.2}\right) \mathrm{Cr}_{2} \mathrm{O}_{4}$ and indicates that the material can be isolated as single-phase crystallizes in a cubic spinel structure (space group $F d-3 m$ ) with $\mathrm{a}=\mathrm{b}=\mathrm{c}=8.3233$ (1) $\AA$. The crystal structure is shown in the figure 1 (b). The octahedrally coordinated $\mathrm{Cr}$ atom occupy the $\mathrm{B}$ site of the structure. $\mathrm{Mg}, \mathrm{Co}, \mathrm{Ni}, \mathrm{Cu}, \mathrm{Zn}$ occupy the eightfold tetrahedral A sites. Figure 1 (c) illustrates the representative SEM image of the material. To determine the chemical composition, corresponding distribution and chemical homogeneity, we have carried out EDS elemental mapping.
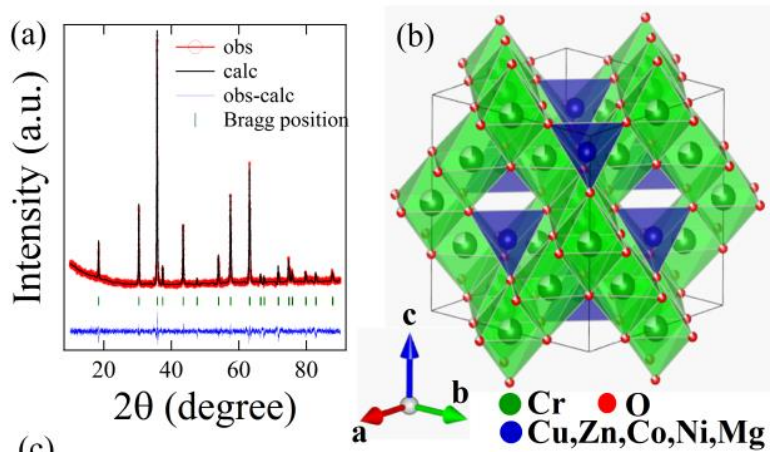

(c)

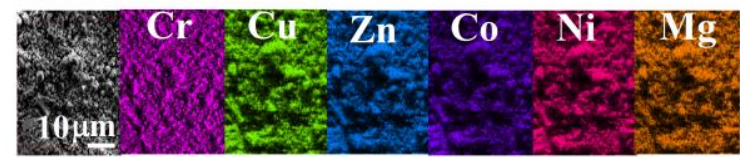

Figure 1. (a) Le Bail profile fit of the room temperature powder $\mathrm{X}$-ray diffraction pattern and (b) crystal structure for the $\left(\mathrm{Mg}_{0.2} \mathrm{Co}_{0.2} \mathrm{Ni}_{0.2} \mathrm{Cu}_{0.2} \mathrm{Zn}_{0.2}\right) \mathrm{Cr}_{2} \mathrm{O}_{4}$ material. (c) A representative SEM image and EDS elemental mapping results for the same material.
As illustrated in Fig. 1 (c), EDS mapping confirms the stoichiometric chemical composition and highlights that all elements are uniformly distributed at the micrometre scale in the sample. Figure 2 shows STEM -ABF and HAADF images of the $\left(\mathrm{Mg}_{0.2} \mathrm{Co}_{0.2} \mathrm{Ni}_{0.2} \mathrm{Cu}_{0.2} \mathrm{Zn}_{0.2}\right) \mathrm{Cr}_{2} \mathrm{O}_{4}$ material. Also, the EDS analysis performed on numerous crystallites during the STEM studies shows good compositional homogeneity and confirms the stoichiometric cationic compositions at the nanoscale. The STEM images shown in figure 2 are consistent with the expected spinel structure along [110] zone axis. Inset in figure 2(c) highlights the electron diffraction (ED) on the same crystallite. The brightest reflections in the ED patterns can be indexed on a cubic unit cell with the cell parameters determined from the room temperature powder XRD pattern. These reflections are typical for a spinel structure. Also, the observed lattice parameter $(8.4 \AA)$ from STEM images matched well with the value found from the XRD refinement.

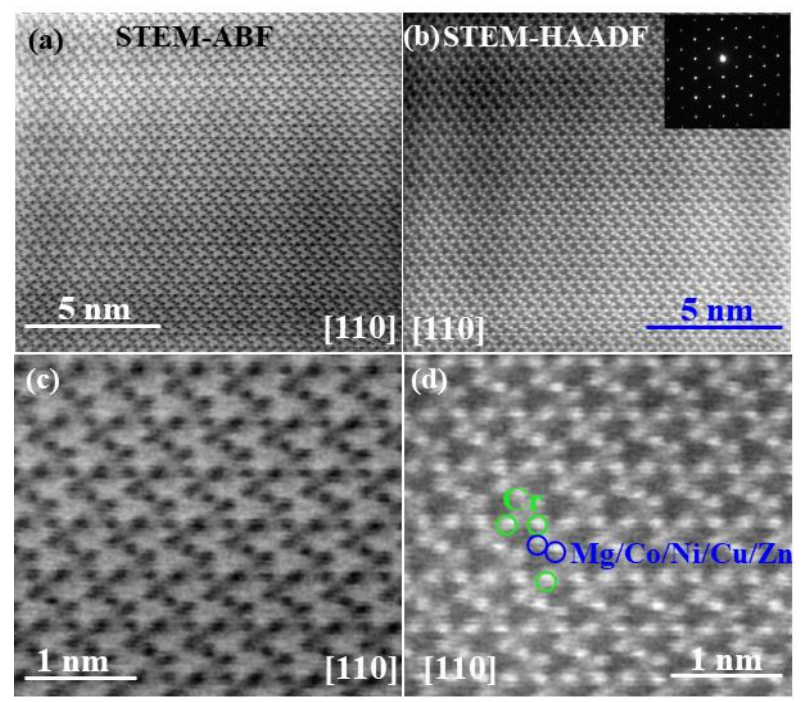

Figure 2. Room temperature (a) STEM-ABF and (b) STEMHAADF images along [110] zone axis for $\left(\mathrm{Mg}_{0.2} \mathrm{Co}_{0.2} \mathrm{Ni}_{0.2} \mathrm{Cu}_{0.2} \mathrm{Zn}_{0.2}\right) \mathrm{Cr}_{2} \mathrm{O}_{4}$ material. Inset in figure (b) shows the electron diffraction pattern on the same crystallite along [110] zone axis. Enlarged views of both images are shown in (c) and $(d)$.

3.2. Magnetic properties and Specific heat. Figure 3 (a) shows the temperature variation $(5-300 \mathrm{~K})$ of the $\mathrm{dc}$ - magnetic susceptibility data measured at $1 \mathrm{~T}$. The field cooled (FC) and zero field cooled (ZFC) magnetic susceptibility do not show any irreversibility down to $25 \mathrm{~K}$. However, a clear peak indicative of an antiferromagnetic (AFM) transition is observed at $35 \mathrm{~K}$ in both the FC and ZFC measurements. It is noteworthy that up to $35 \mathrm{~K}$, the magnetic susceptibility continues to increase with lowering the temperature, and this is somewhat expected for a strongly disordered system. Similar behavior is recently observed in the HEO material $\left(\mathrm{Mg}_{0.2} \mathrm{Co}_{0.2} \mathrm{Ni}_{0.2} \mathrm{Cu}_{0.2} \mathrm{Zn}_{0.2}\right) \mathrm{O}$ below its $\mathrm{AFM}\left(\mathrm{T}_{\mathrm{N}}=113\right.$ $\mathrm{K})$ ordering temperature $[11,13]$. The Curie-Weiss $[\chi=\mathrm{C} /(\mathrm{t}-$ $\left.\theta_{\mathrm{Cw}}\right), \mathrm{C}=$ Curie constant, $\theta_{\mathrm{CW}}=$ Curie-Weiss temperature $]$ fitting in the high-temperature region $(150-300 \mathrm{~K})$ of the inverse of the FC magnetic susceptibility measured at $1 \mathrm{~T}$ leads to an effective paramagnetic (PM) magnetic moment ( $\left.\mu_{\text {eff }}\right)$ of $6.03 \mu_{\mathrm{B}}$. We have subtracted the core diamagnetic contributions of all the elements from the susceptibility plot. The observed paramagnetic moment shows an excellent match with the expected theoretical values calculated on the basis of spin only contributions of all the transition metal elements $\left(\mu_{\text {theoritical }}=5.93 \mu_{\mathrm{B}}\right)$. The negative sign of 
Curie-Weiss temperature $\left(\theta_{\mathrm{CW}}=-459 \pm 1 \mathrm{~K}\right)$ highlights the predominant AFM type spin correlations. The high value of $\theta_{\mathrm{cw}}$ indicates very high frustration (frustration index $\mathrm{f}=\left|\theta_{\mathrm{CW}}\right| / \mathrm{T}_{\mathrm{N}} \sim$ 13) in the system. Magnetization measurements as a function of the magnetic field $(\mathrm{M}-\mathrm{H})$ at different fixed temperatures are shown in figure 3 (b). Typical unsaturated AFM type hysteresis loops are observed. A small coercive field, indicating the magnetic frustration in the material is observed in the M-H loop measured at $5 \mathrm{~K}$. Besides the high frustration index observed in the Curie-Weiss fitting, due to existence of several magnetic and nonmagnetic cations and their random distribution in the A- site of the crystal structure, one may at a glance expect a spin-glasslike magnetic state. Also, it has been already shown that the doping in the A site of the chromium spinel leads to the spin glass type magnetic behavior [34].
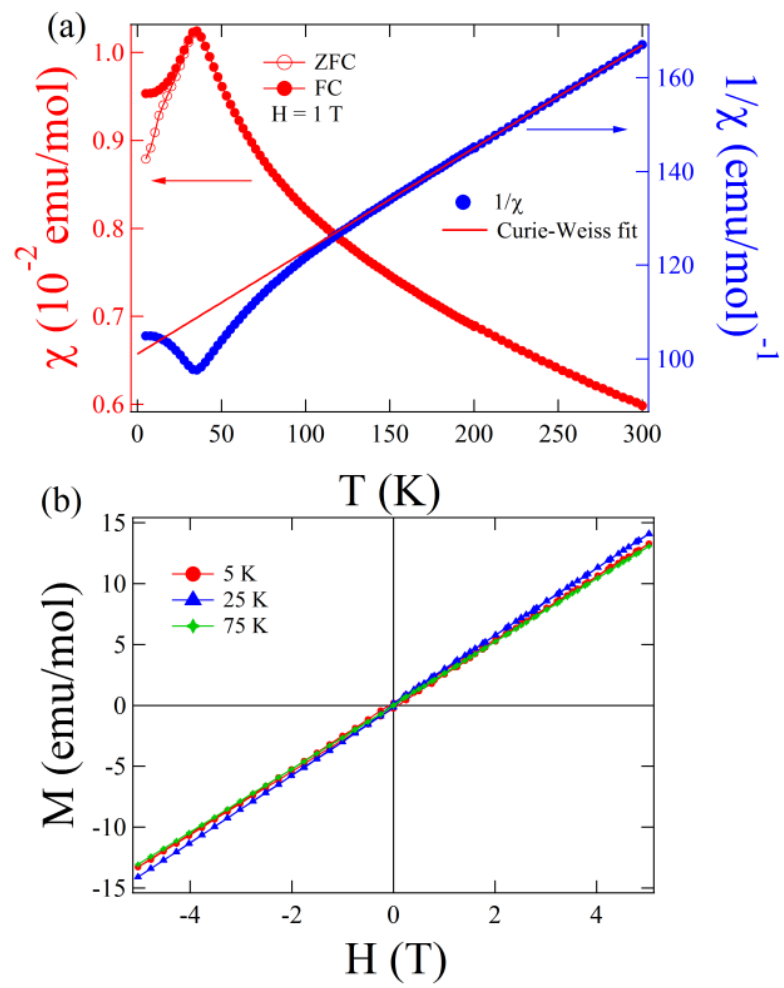

Figure 3. (a) Temperature variation of the magnetic susceptibility (left axis) and the inverse of the FC magnetic susceptibility (right axis) measured at $1 \quad \mathrm{~T}$ magnetic field for $\left(\mathrm{Mg}_{0.2} \mathrm{Co}_{0.2} \mathrm{Ni}_{0.2} \mathrm{Cu}_{0.2} \mathrm{Zn}_{0.2}\right) \mathrm{Cr}_{2} \mathrm{O}_{4}$ material. (b) Magnetic field variation of the magnetization at different fixed temperature for the same material.

Therefore, to know the exact nature of the magnetic interaction and to verify the possibility of the spin-glass transition, we have carried out the temperature dependence of the ac susceptibility measurements at different ac frequencies. Figure 4 shows the temperature variation of the real $\left(\chi^{\prime}\right)$ and imaginary $\left(\chi^{\prime \prime}\right)$ part of the ac susceptibility measured at various frequencies. Similar to the dc susceptibility measurements, a peak is observed at $35 \mathrm{~K}$ in the real part of the ac susceptibility data. However, no peak is observed in the imaginary part near this transition. Also, no frequency-dependent shift of the peak is observed in the ac susceptibility data. All these observations unambiguously indicate a longrange antiferromagnetic order and absence of a spin glass type freezing. It is important to note here that, all the chromium spinels having magnetic cations in the A site of the structure shows long range ferrimagnetic (FIM) ordering (for instance, $\mathrm{CoCr}_{2} \mathrm{O}_{4}$ shows FIM at $97 \mathrm{~K}$ [30], for $\mathrm{NiCr}_{2} \mathrm{O}_{4} \mathrm{~T}_{\mathrm{C}}=75 \mathrm{~K}$ [35], for $\mathrm{CuCr}_{2} \mathrm{O}_{4} \mathrm{~T}_{\mathrm{C}}=$ $120 \mathrm{~K}$ [35]). Quite interestingly, the present material, despite of having a disordered $\mathrm{A}$ site (and therefore various $\mathrm{A}-\mathrm{O}-\mathrm{Cr}$ interactions) and having the effect of different crystal fields on $\mathrm{Cr}$ site shows predominant AFM ordering at $35 \mathrm{~K}$. The irreversibility between FC and ZFC susceptibility observed at $20 \mathrm{~K}$ could be due to the spin reorientation or lock-in transition (the crossover from incommensurate to commensurate phase) commonly observed in spinel structure [24,30,33]. However, further experimental and theoretical studies (such as neutron diffraction, inelastic neutron scattering and pair distribution function calculations) are required to know the exact nature of the spin structure of this interesting high entropy system.

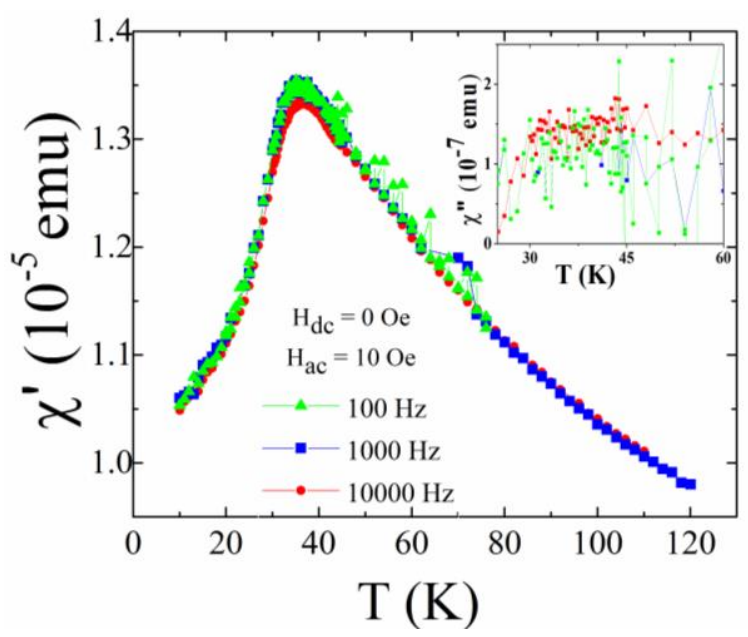

Figure 4. Temperature variation of the real part of ac - magnetic susceptibility $\left(\chi^{\prime}\right)$ for $\left(\mathrm{Mg}_{0.2} \mathrm{Co}_{0.2} \mathrm{Ni}_{0.2} \mathrm{Cu}_{0.2} \mathrm{Zn}_{0.2}\right) \mathrm{Cr}_{2} \mathrm{O}_{4}$ material. Inset highlights the absence of a peak in the imaginary part of the ac-susceptibility data.

Further, we have performed temperature dependent heat capacity measurement in the absence of an external magnetic field to investigate the magnetic ordering. As shown in figure 5, in an agreement with the magnetic measurements, a hump like peak is prominent $\sim 35 \mathrm{~K}$ and this confirms the long range nature of the magnetic transition.

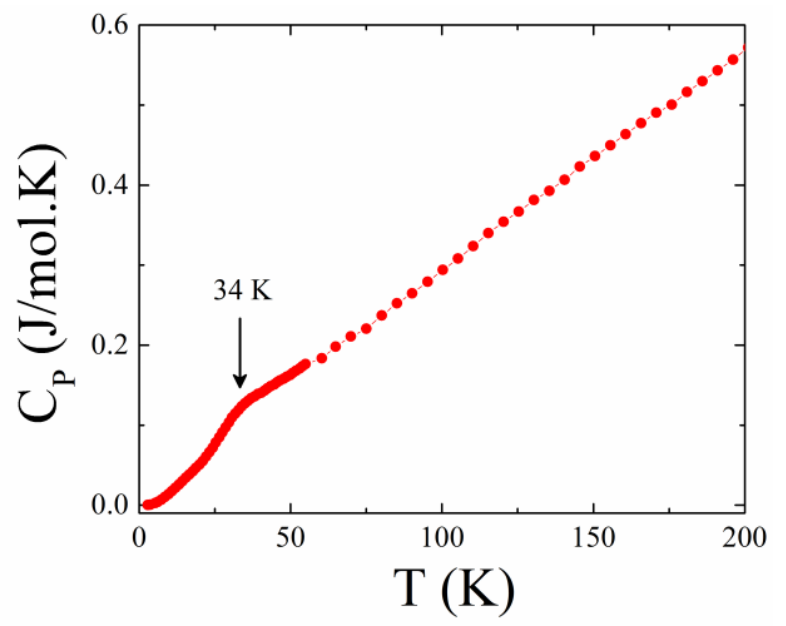

Figure 5. Temperature variation of specific heat for $\left(\mathrm{Mg}_{0.2} \mathrm{Co}_{0.2} \mathrm{Ni}_{0.2} \mathrm{Cu}_{0.2} \mathrm{Zn}_{0.2}\right) \mathrm{Cr}_{2} \mathrm{O}_{4}$ material. 


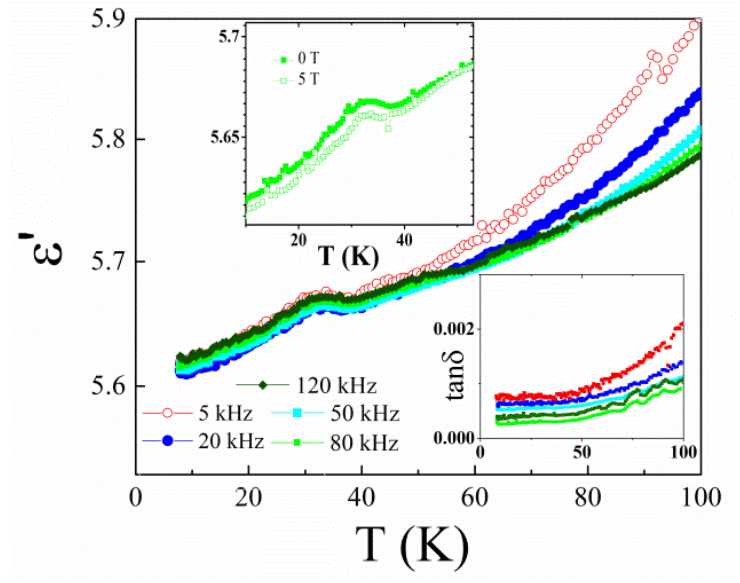

Figure 6. Real part of dielectric constant $\left(\varepsilon^{\prime}\right)$ as a function of temperature for $\left(\mathrm{Mg}_{0.2} \mathrm{Co}_{0.2} \mathrm{Ni}_{0.2} \mathrm{Cu}_{0.2} \mathrm{Zn}_{0.2}\right) \mathrm{Cr}_{2} \mathrm{O}_{4}$ material. Lower inset shows the loss part $(\tan \delta)$. Magnetic field dependence of the dielectric constant for the same material is shown in the upper inset of the figure.

3.3. Dielectric properties. Figure 6 shows the temperature variation of the dielectric constants for $\left(\mathrm{Mg}_{0.2} \mathrm{Co}_{0.2} \mathrm{Ni}_{0.2} \mathrm{Cu}_{0.2} \mathrm{Zn}_{0.2}\right) \mathrm{Cr}_{2} \mathrm{O}_{4}$ measured below $100 \mathrm{~K}$. The very low value of $\tan \delta$ (dielectric loss) reveals highly insulating nature of the sample. Both the dielectric constant and loss show that the frequency dispersion started above $60 \mathrm{~K}$. This indicates the growing Maxwell-Wagner type relaxation or another source of conductivity above $60 \mathrm{~K}$ and the dielectric constants are intrinsic below this temperature. Interestingly, a clear peak at the AFM ordering is observed in the dielectric data, indicating the possibility of magneto-electric coupling at this temperature. Magnetoelectric coupling due to the incommensurate spin-spiral structure at low temperature is already observed in the chromium based spinel samples at low temperature (for instance, in $\mathrm{CoCr}_{2} \mathrm{O}_{4}$ at 26 $\mathrm{K})$ [30]. In such cases, at spiral magnetic transition, the inverse Dzyloshinskii-Moriya (DM) interaction $\left(D_{n, n+1} \cdot S_{n} \times S_{n+1}, D_{n, n+1}\right.$ is the Dzyaloshinskii vector) due to the spiral spin ordering breaks the inversion symmetry at neighboring sites of non-collinear spins and produces ferroelectricity $[30,36]$. Also, in the presence of a magnetic field, the dielectric constant for the present materials starts to decrease near the AFM temperature, and a negative magnetocapacitance effect is observed below this temperature.

\section{Conclusions}

In conclusion, we have synthesized and studied a new high entropy spinel oxide. The SEM-EDS elemental mapping, X-ray diffraction, and STEM ABF and HAADF measurements show that the sample crystallizes in a cubic spinel structure with an excellent chemical homogeneity at the nanoscale. The dc, ac magnetometry and specific heat show a long range antiferromagnetic ordering at $35 \mathrm{~K}$ in this highly disordered single-phase material. It is remarkable that the present material, despite of having a disordered $\mathrm{A}$ site (and therefore various $\mathrm{A}-\mathrm{O}-\mathrm{Cr}$ interactions) and having the effects of different crystal fields on $\mathrm{Cr}$ site shows long range magnetic ordering at $35 \mathrm{~K}$. Magnetic measurements highlight a high magnetic frustration ( $\left.\mathrm{f}=\left|\theta_{\mathrm{CW}}\right| / \mathrm{T}_{\mathrm{N}} \sim 13\right)$ in the system. The disorder (both magnetic and structural) and the presence of Jahn-Teller active cations $(\mathrm{Cu}$ and $\mathrm{Ni}$ ) in the structure could be the reason of the magnetic correlations in this material remain frustrated, however, with a long-range magnetic ordering at $35 \mathrm{~K}$. A peak in the dielectric measurement likely due to the possible magneto-electric effect is observed at the AFM ordering temperature. Further investigations (both theoretical and experimental) on this new material are warranted in order to underpin the exact nature spin configuration correlation and mechanism of MD coupling in this disordered material.

\section{AUTHOR INFORMATION}

\section{Corresponding Author}

soumarik@gmail.com

The authors declare no competing financial interests.

\section{ACKNOWLEDGMENT}

SM acknowledges the financial support of the Universite de Caen for this work. The authors acknowledge the financial support of the french Agence Nationale de la Recherche (ANR), through the program "Investissements d'Avenir"(ANR-10-LABX-09-01), LabEx EMC3.

\section{REFERENCS}

(1) D. B. Miracle, O. N. Senkov, Acta Mater. 122 (2017) 448-511.

(2) Y. F. Ye, Q. Wang, J. Lu, C. T. Liu and Y. Yang, Materials Today, 19 (2016) 349-362.

(3) J.-W. Yeh, S.-K. Chen, S.-J. Lin, J.-Y. Gan, T.-S. Chin, T.-T. Shun, C.-H. Tsau and S.-Y. Chang Advanced Engineering materials 6 (2004) 299.

(4) P. Koželj, S. Vrtnik, A. Jelen, S. Jazbec, Z. Jagličić, S. Maiti, M. Feuerbacher, W. Steurer, and J. Dolinšek Phys. Rev. Lett. 113 (2014) 107001.

(5) Sourav Marik, Kapil Motla, Maneesha Varghese, K. P. Sajilesh, Deepak Singh, Y. Breard, P. Boullay, and R. P. Singh, Phys. Rev. Materials 3 (2019) 060602(R).

(6) E. P. George, D. Raabe, and R. O. Ritchie, Nat. Rev. Mater. 4 (2019) 515-534.

(7) A. Biswas, A. K. Pathak, N. A. Zarkevich, L. Xuboa, Y. Mudryk, V. Balema, D. D.Johnson, V. K.Pecharsky, Acta Mater. 180 (2019) 341-348.

(8) C. M. Rost, E. Sachet, T. Borman, A. Moballegh, E. C. Dickey, D Hou, J. L. Jones, S. Curtarolo, J.-P. Maria, Nat. Commu. 6 (2015) 8485.

(9) A. Sarkar, Q. Wang, A. Schiele, M. R Chellali, S. S. Bhattacharya, D. Wang, T. Brezesinski, H. Hahn, L. Velasco, B. Breitung, Adv. Mater. 31 (2019) 1806236.

(10) A. Sarkar, L. Velasco, D. Wang, Q. Wang, G. Talasila, L. D. Biasi, C. Kübel, T. Brezesinski, S. S. Bhattacharya, H. Hahn, Nat. Commu. 9 (2018) 3400.

(11) J. Zhang, J. Yan, S. Calder, Q. Zheng, M. A. McGuire, D. L. Abernathy, Y. Ren, S. H. Lapidus, K. Page, H. Zheng, J. W. Freeland, J. D. Budai, R. P. Hermann, Chem. Mater. 3110 (2019) 3705-3711.

(12) G.Anand, A. P.Wynn, C. M.Handley, C. L. Freeman, Acta Mater. 146 (2018) 119-125.

(13) M. P. Jimenez-Segura , T. Takayama , D. Bérardan , A. Hoser, M. Reehuis , H. Takagi and N. Dragoe , Appl. Phys. Lett. 114 (2019) 122401.

(14) R. Witte, A. Sarkar, R. Kruk, B. Eggert, R. A. Brand, H. Wende, H. Hahn, Phys. Rev. Mater. 3 (2019) 034406.

(15) B. Ye, T. Wen, M. C. Nguyen, L. Hao, C. -Z. Wang, Y. Chu, Acta Mater. 170 (2019) 15-23. 
(16) S. Jiang, T. Hu, J. Gild, N. Zhou, J. Nie, M. Qin, T. Harrington, K. Vecchio, J. Luo, Scripta Mater. 142 (2018) 116-120.

(17) Z. Lei, X. Liu, H. Wang, Y. Wu, S. Jiang, Z. Lu, Scripta Mater. 165 (2019) 164-169.

(18) T. J.Harrington, J. Gild, P. Sarker, C. Toher, C. M. Rost, O. F. Dippo, C. McElfresh, K. Kaufmann, E. Marin, L. Borowski, P. E. Hopkins, J. Luo, S. Curtarolo, D. W. Brenner, K. S.Vecchio, Acta Mater. 166 (2019) 271280.

(19) Y. Lederer, C. Toher, K. S.Vecchio, S. Curtarolo, Acta Mater. 159 (2019) 364-383.

(20) D. Liu, T. Wen, B. Yea, Y. Chu, Scripta Mater. 167 (2019) 110-114.

(21) Q. Wang, A. Sarkar, D. Wang, L. Velasco, R. Azmi, S. S. Bhattacharya, T. Bergfeldt, A. Düvel, P. Heitjans, T. Brezesinski, H. Hahn, B. Breitung, Energy Environ. Sci., 12 (2019 2433-2442.

(22) D. Bérardan , S. Franger , A. K. Meena, N. Dragoe , J. Mater. Chem. A 4 (2016) 9536 - 9541.

(23) H. Chen , J. Fu , P. Zhang, H. Peng, C. W. Abney , K. Jie , X. Liu , M. Chi, S. Dai , J. Mater. Chem. A, 6 (2018) 11129 - 11133

(24) D. Bérardan, S. Franger, D. Dragoe, A. K. Meena, N. Dragoe Physica status solidi (RRL)-Rapid Research Letters 10 (2016) 328-333.

(25) A. Sarkar , C. Loho , L. Velasco , T. Thomas , S. S. Bhattacharya , H. Hahn, R. Djenadic , Dalton Trans., 46 (2017) 12167-12176.

(26) D. Das, S. Ghosh, J. Phys. D: Appl. Phys. 48 (2015) 425001

(27) S.-H. Lee, C. Broholm, T. H. Kim, W. Ratcliff, II, S-W. Cheong Phys. Rev. Lett. 84 (2000) 3718.

(28) J.-H. Chung, M. Matsuda, S.-H. Lee, K. Kakurai, H. Ueda, T. J. Sato, H. Takagi, K.-P. Hong, S. Park, Phys. Rev. Lett. 95 (2005) 247204.

(29) K. Tomiyasu, J. Fukunaga, H. Suzuki, Phys. Rev. B 70 (2004) 214434.

(30) Y. Yamasaki, S. Miyasaka, Y. Kaneko, J.-P. He, T. Arima, Y. Tokura Phys. Rev. Lett. 96 (2006) 207204.

(31) D. Kim, S. Ihm, Environ. Sci. Technol. 351 (2001) 222-226.

(32) C. Wen, B. Hershenov, H. Philipsborn, H. Pinch IEEE Transections on Magnetics 4 (1968) 702-704.

(33) H. Cui, M. Zayat, D. Levy, J. Sol-Gel Sci. Technol. 35 (2005) 175-181.

(34) H. Martinho, N. O. Moreno, J. A. Sanjurjo, C. Rettori, A. J. García-Adeva, D. L. Huber, S. B. Oseroff, W. Ratcliff, II, S.-W. Cheong, P. G. Pagliuso, J. L. Sarrao, G. B. Martins Phys. Rev. B 64 (2001) 024408.

(35) M. R. Suchomel, D. P. Shoemaker, L. Ribaud, M. C. Kemei, and R. Seshadri Phys. Rev. B 86 (2012) 054406.

(36) G. Lawes, B. Melot, K. Page, C. Ederer, M. A. Hayward, Th. Proffen, R. Seshadri Phys. Rev. B 74 (2006) 024413 . 
TOC Figure

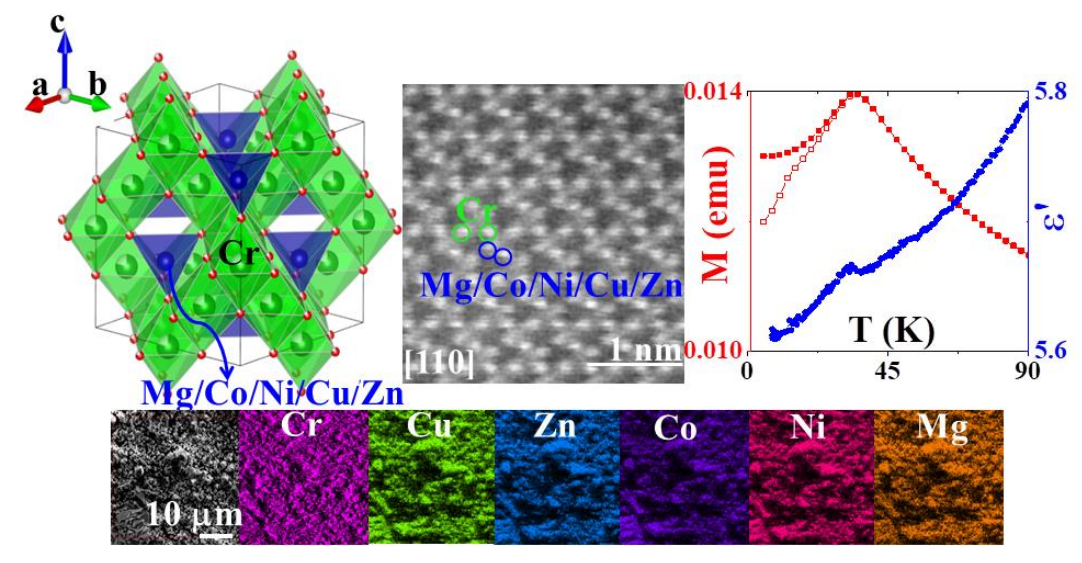

